\title{
Access to financing, rents, and organization of the firm ${ }^{\text {is }}$
}

\author{
Antoine Renucci* \\ Université Paris-Dauphine, DRM, F-75016 Paris, France \\ CNRS, UMR7088, F-75016 Paris, France
}

\section{A R T I C L E I N F O}

\section{Article history:}

Received 13 December 2004

Received in revised form 4 March 2008

Accepted 7 March 2008

Available online 18 March 2008

\section{JEL classification:}

G3

\section{Keywords:}

Unitary-form

Multidivisional-form

Agency rents

Credit rationing

\begin{abstract}
A B S T R A C T
This paper provides a theory for the choice of an organizational structure by the headquarters of a unitary structure concerned about overload. The headquarters can avoid overload by delegating operational decisions to divisions, i.e., moving the firm to a multidivisional structure. We show that, under moral hazard, these divisions receive rents for incentive purposes, and that the multidivisional structure is able to invest more. Thus, there is a trade-off between increasing investment and paying rents. We also show that this trade-off applies to situations where firms consider engaging in acquisitions and joint ventures, or where entrepreneurs consider resorting to venture capitalists.
\end{abstract}

(c) 2008 Elsevier B.V. All rights reserved.

\section{Introduction}

Growth is a major objective for most firms. All types of organizations cannot accommodate expansion though. For instance, within unitary-form (U-form) structures, expanding activities rapidly causes the headquarters' overload since headquarters make both strategic and operational decisions (Chandler, 1966; Williamson, 1975). A solution is to adopt a multidivisional form (M-form), i.e., to delegate operational decisions to divisions (Simon, 1973). However, the choice of a structure cannot reduce to the overload issue since delegating operational decisions impacts on incentives (Arrow, 1974). In this paper, we provide a theory for the choice of an organizational structure by a headquarters against the backdrop of the overload issue when moral hazard plagues strategic and operational decision making. We extend our theory to analyze the decision to engage in acquisitions and joint ventures or resort to venture capitalists.

Consider a headquarters running a U-form enterprise that has two independent projects with the same potential. Each project is profitable if a relevant strategic decision and a relevant operational decision are made. Capabilities being limited, the headquarters cannot make the four decisions. Optimally, a headquarters willing to run the largest possible firm would delegate operational decisions to divisions, i.e., make the firm adopt the M-form, and the firm would realize the two projects.

Under moral hazard, things are quite different. From the headquarters' perspective, the drawback of the M-form is that rents must optimally be left to the divisions. The reason is the following. Making efficient operational decisions requires costly

\footnotetext{
is This paper is a revised version of Chapter 2 of my Ph.D. dissertation. Part of the revision took place while I was visiting the Saïd Business School, University of Oxford. I am indebted to Bruno Biais, Jeffry Netter (the editor), and to an anonymous referee for their encouragement and advice. I am grateful to Catherine Casamatta, Mike Fishman, Edith Ginglinger, Fred Loss, Thomas Mariotti, Clotilde Napp, Rafael Repullo, Jean-Charles Rochet and Jean Tirole for their insightful comments. Many thanks also to participants to the 2001 AFFI conference in Namur, the Gremaq Séminaire Jeunes, the 2002 IDEI-ESCT Finance Workshop, the 2002 EFMA meetings in London, and the 2002 ESEM in Venice. I acknowledge the support of the Chaire de Finance d'Entreprise funded by the Fédération Bancaire Française. All remaining errors are mine.

* DRM-Finance (CEREG), Université Paris-Dauphine, Place du Maréchal de Lattre de Tassigny, 75775 Paris cedex 16, France. Tel.: +33 1440545 17; fax: +33 144 054023.

E-mail address: antoine.renucci@dauphine.fr.
} 
unobservable efforts of investigation. Thus divisions must be provided with adequate incentives. When the cash-flows (per unit of investment) divisions receive for incentive purposes are lower than the (per unit of investment) net present value (NPV), the headquarters makes a profit on each unit of investment realized. Thus, investing as much as possible in the two projects is best. Investment is not infinite, however, since strategic decision making also requires costly unobservable efforts from the headquarters, which raises the burden of moral hazard on financing capacity. Reaching this limit makes divisions receive rents, i.e., cash-flows in excess of their financial contribution. Within the U-form, moral hazard problems, although of the same intensity, interact differently: Being the only agent to make decisions, the headquarters earns all the NPV.

The advantage of the M-form is its larger investment capacity, and the resulting larger profits. Two independent (but complementary) reasons explain this pattern. First, under the M-form, the headquarters can pay back investors with the cashflows of a successful division when the other division fails. Cross-pledging raises investment capacity. Second, more external funds can be raised under the M-form since "internal" resources are - endogenously - larger. Indeed, a headquarters that organizes the firm as an M-form is better off not creating two divisions from scratch. External growth should be privileged since the M-form then benefits from all the financial resources of the unit it integrates (this unit accepts to become part of the firm since the cash-flows it subsequently receives for incentive purposes outweigh its financial contribution, as discussed above). In contrast, a headquarters that keeps running a U-form and sells out one project to obtain additional resources for the other project must charge a price strictly lower than the acquirer's financial resources. If not, the acquirer is left with no assets, which reduces its stake in the project, thus its incentives, and in turn prevents it from obtaining funds.

Overall, the headquarters prefers the M-form if operational moral hazard is low, so that the divisions' rents are small, or if the firm it can integrate is rich. As discussed above, the resources of the latter have more value within an M-form. Thus, the investment capacity effect outweighs the rent effect if these resources are sufficient. Otherwise, the U-form is optimal, i.e., growth is rejected by the headquarters. We derive empirical implications from these results. We delay their exposition after we present formally our theory.

A slight modification of our initial framework allows us to consider other institutional arrangements. We first consider a firm that can acquire other companies just to benefit from their financial resources. Next, we consider a firm that can set up a joint venture with another company to benefit from its expertise on a specific task that is necessary to complete a project. Finally, we consider the founder of a start-up firm who contemplates asking a venture capitalist to help him, which is not necessary to complete the founder's project. In all these instances, adding an agent increases investment capacity and in turn profits, but implies to share these profits, so that it is worth if the agent puts enough funds in.

Our research differs from agency literature that compares U- and M-forms since our focusing on strategic and operational decisions allows us to bring headquarters in, and thus, to address the overload issue. In contrast, existing research (e.g., Inderst et al., 2007) has little to say about headquarters' overload since it focuses on the separation of tasks among units (i.e., the U-form groups activities by functions such as Production and Marketing, whereas the M-form groups activities by products). The exception is Aghion and Tirole (1995). They conclude that, in their framework, one "should be theoretically agnostic about the overload explanation" of moving to the M-form, but do not characterize formally the conditions under which the U-form dominates. In this respect, our paper fills a gap in the literature. By endogenizing the projects' size, we show that rents and investment capacity are critical factors: Overload alone cannot explain the change of structure. Focusing on the separation of tasks among units allows existing theoretical research to compare the efficiency of M- and U-forms in allocating resources (Williamson, 1975; Inderst et al., 2007), providing incentives (Williamson, 1975; Maskin et al., 2000), and favoring cooperation (Crémer, unpublished manuscript). Within M-forms, the distinct profit centers (divisions), each for one product, should facilitate the transfer of resources to their most profitable uses ${ }^{1}$ and provide division managers with more effective incentives because it avoids moral hazard in teams (Williamson, 1975). Since the U-form can at most realize one project in what follows, the two structures are on a level playing field in these respects. The distinct profit centers should also allow yardstick competition between divisions facing (some) common economic conditions, and thus foster incentives (Maskin et al., 2000). ${ }^{2}$ This argument in favor of M-forms is neutralized here since projects are independent. It is meant to reflect that though theoretically seducing, this type of competition is not that widespread in practice.

Next, the present paper is connected to recent financial literature that compares stand-alone and integrated firms by analyzing the efficiency of internal capital markets within the latter, i.e., the transfers of resources between divisions, by the headquarters (see Stein, 2003; Martin and Sayrak, 2003, for surveys). A prominent force of internal capital markets is the cross-pledging of cashflows, or coinsurance effect identified by Lewellen (1971), that we extend here to the case where moral hazard has two dimensions and is double-sided. A first point of departure of our paper from this literature is that we let the projects' size depend on the funds that can be raised externally, which is quite natural in most circumstances. In this context, overinvestment as in Matsusaka and Nanda (2002), and strategic defaulting on the repayment of current debt as in Inderst and Müller (2003) have no bite. These problems arise when retained earnings are sufficient to finance future investments so that integrated firms are insulated from external capital market discipline. A second point of departure of our paper from this literature is that we assume that the projects' profitability is identical and is common information. Thus, we avoid entering the ongoing debate as to whether integrating productive units modifies financing costs by impacting on information asymmetry (e.g., Krishnaswami and Subramanian, 1999; Huson and MacKinnon, 2003; Clarke et al., 2004; Berkovitch et al., 2006). Also, we can avoid addressing the controversial issue of

\footnotetext{
${ }^{1}$ However, U-forms are shown to have a higher ability to cope with resource allocation conflicts between divisions when firms have fewer products than functions (Inderst et al., 2007).

2 The efficiency issue has also been addressed outside the agency literature. Qian et al. (2006) show that M-forms are more flexible in choosing the scale of experimentation of uncertain projects, whereas U-forms are technically more efficient since units can specialize on specific functions. Qian et al. (2006) further show that $\mathrm{M}$ - and U-forms have differing advantages regarding coordination.
} 
whether integrated firms misallocate resources (e.g., see Ahn and Denis, 2004; McNeil and Moore, 2005, for somewhat opposing, recent results). Here, there is no room for "winner-picking" by headquarters (Stein, 1997) and the related positive effect of linking future funding to future profitability on the divisions' incentives to find good projects (Inderst and Laux, 2005). There is no room either for the dark side of winner-picking: Low effort (Stein, 1997; Brusco and Panunzi, 2005), rent-seeking ${ }^{3}$ and power-struggling by some divisions (Harris et al., 1982; Meyer et al., 1992; Rajan et al., 2000; Scharfstein and Stein, 2000).

The rest of the paper is organized as follows. We present the model in Section 2. We analyze the different organizational structures in Section 3. In Section 4, we examine the headquarters' preferred arrangement, derive empirical implications, and offer other interpretations of the basic framework. Conclusions follow. We supply the proof of Proposition 3 in Appendix A.

\section{The model}

Firm $f$ has currently a U-form structure, is endowed with financial resources $A$ generated by past activities, and has two investment projects.

The two projects are statistically independent and financially identical. Investment is continuous-size. The amount $I_{j}$ (with $j=1,2$ ) invested in project $j$ not only depends on internal resources but also on the funds that can be raised from outside investors. Each project succeeds with probability $p$ and fails with probability $(1-p)$. Let $p=p_{h}$ if and only if a relevant strategic decision and a relevant operational decision are simultaneously made. Making a relevant decision requires unobservable costly investigation efforts. Hence, moral hazard has two sources, each corresponding to one kind of decision. Following Holmström and Tirole (1997), we assume that the agent in charge of a decision either "works" or "shirks". Working enables to make a relevant decision. Shirking is incompatible with efficient decision making but provides a private benefit (or equivalently avoids a costly effort) $B_{s} I_{j}$ (respectively, $B_{0} I_{j}$ ) regarding the strategic (respectively, operational) decision. If either the relevant strategic choice or the relevant operational choice is not made, the probability of success of a project decreases from $p_{h}$ to $p_{l}$ (with $p_{l}<p_{h}$ ). Project $j$ yields $R I_{j}$ when it succeeds and zero when it fails. If $p=p_{h}$, the project exhibits a positive NPV per unit of investment: $p_{h} R-1 \geq 0$. If $p=p_{\text {l, }}$, the NPV per unit of investment is strictly negative.

A prominent feature of $\mathrm{U}$-forms is that headquarters are responsible for both strategic and operational decisions. In contrast, headquarters delegate operational choices to divisions within M-forms. We assume that human capabilities are limited in the sense that an agent can make at most two strategic decisions, or a strategic decision and an operational decision, but not two operational decisions, i.e., managing two divisions at a time is impossible. Thus, the headquarters of $f$, denoted $\mathrm{HQ}_{f}$ in what follows, can (i) maintain the U-form of $f$, realize internally one project and sell out the other project, or (ii) make $f$ adopt the M-form in order to realize the two projects internally. In the latter case, we assume that $\mathrm{HQ}_{f}$ allocates resources efficiently among divisions. There are no exogenous savings or diseconomies from joint production.

There exists another U-form company, $F$, which has no project but is endowed with financial resources $\alpha A$. Investors are competitive. Every party is risk-neutral and protected by limited liability.

We also make a couple of technical assumptions. First, moral hazard problems are sufficiently pronounced to have the investment level finite in equilibrium: $p_{h}\left(\frac{B_{0}+(1-\lambda) B_{s}}{\Delta p}\right)>p_{h} R-1$, with $\Delta p \stackrel{d}{=} p_{h}-p_{l}$ and $\lambda \stackrel{d}{=} \frac{p_{l}}{p_{l}+p_{h}}$. Next, each moral hazard problem is sufficiently limited to allow us to focus on the case where both $\mathrm{HQ}_{f}$ and the divisions receive strictly positive net agency rents in equilibrium under the M-form: $p_{h} \frac{B_{s}}{\Delta p}<p_{h} R-1$ and $p_{h} \frac{B_{0}}{\Delta p}<p_{h} R-1$. Also, inducing $\mathrm{HQ}_{f}$ to work must not be impossible. Thus, $\frac{B_{0}+B_{s}}{\Delta p}<R$ is required. Finally, setting $p_{l} \geq \frac{1}{2}$ simplifies the incentive scheme under the M-form.

In the next section, we consider the sharing rules of the cash-flows between firms and investors, or within firms, that allow projects to be funded.

\section{Organizational structures}

We successively examine two cases. In the first case, $\mathrm{HQ}_{f}$ maintains the U-form structure of $f$ and sells out one of the projects. In the second case, $\mathrm{HQ}_{f}$ changes the structure of $f$, i.e., moves $f$ to the M-form, and undertakes the two projects internally.

\subsection{Keeping the U-form structure and selling out one project}

Without loss of generality, assume that $\mathrm{HQ}_{f}$ realizes project 1 and sells out project 2. Consider project $1 . \mathrm{HQ}_{f}$ and the investors earn nothing when the project fails since the cash-flows are then equal to zero and all parties are protected by limited liability. $I_{1}^{U}$ denotes the level of investment, $D_{1}^{U}$ the payment to the investors when project 1 succeeds, and $P$ the price received from the sale of project 2. The objective of $\mathrm{HQ}_{f}$ is to maximize its net expected revenue, i.e., the expected cash-flows of the project net of any payment to the investors, or $p_{h}\left(R I_{1}^{U}-D_{1}^{U}\right)$. The following constraints must be satisfied.

First, $\mathrm{HQ}_{f}$ must perform the level of investigation effort compatible with proper decision making. It requires that its revenue should be larger when it works than when it shirks (private benefit included), as summarized in Eq. (1). ${ }^{4}$ Observe that $\mathrm{HQ}_{f}$ 's potential private

\footnotetext{
${ }^{3}$ Resource misallocation can also result from, e.g., managerial entrenchment (Shleifer and Vishny, 1989), empire building (Jensen, 1986; Aggarwal and Samwick, 2006), and diversification of human capital (Amihud and Lev, 1981).

4 Two remarks are in order here. First, the headquarters works when indifferent between doing so and enjoying a private benefit. This pattern applies to every agent in the model. Second, in limited liability absence, the design of the agents' incentives would be facilitated since agents could be punished when their project fails, e.g., be inflicted a non-monetary punishment such as being sent to jail. However, the absence of limited liability would not modify the essence of our results.
} 
benefit amounts to $\left(B_{O}+B_{S}\right) I_{1}^{U}$ since $\mathrm{HQ}_{f}$ is in charge of strategic and operational decisions. Also observe that $\mathrm{HQ}_{f}$ prefers shirking on both decisions to shirking on one decision since the probability of success of the project decreases from $p_{h}$ to $p_{l}$ if a decision is not adequate.

Second, $\mathrm{HQ}_{f}$ must recoup the funds it invested in project 1, i.e., the initial resources $A$ plus the price $P$ received from the sale of project 2 (characterized in Eq. (8) below), which is summarized in Eq. (2).

Third, investors must recoup the funds they invested, i.e., $I_{1}^{U}-(A+P)$, which is summarized in Eq. (3).

Thus, $\mathrm{HQ}_{f}$ solves the following program:

$$
\begin{array}{ll} 
& \max _{I_{1}^{U}, D_{1}^{U}} \quad p_{h}\left(R I_{1}^{U}-D_{1}^{U}\right) \\
\text { s.t. } & p_{h}\left(R I_{1}^{U}-D_{1}^{U}\right) \geq p_{l}\left(R I_{1}^{U}-D_{1}^{U}\right)+\left(B_{0}+B_{S}\right) I_{1}^{U} \\
& p_{h}\left(R I_{1}^{U}-D_{1}^{U}\right) \geq A+P \\
& p_{h} D_{1}^{U} \geq I_{1}^{U}-(A+P) .
\end{array}
$$

The investors' participation constraint, Eq. (3), optimally binds since investors are competitive and not subject to moral hazard. Substituting $D_{1}^{U}=\frac{I_{1}^{U}-(A+P)}{p_{h}}$ into Eq. (1) and reorganizing shows that there exists an upper limit on the level of investment, i.e.,

$$
I_{1}^{U} \leq \frac{A+P}{1-p_{h}\left(R-\frac{B_{0}+B_{s}}{\Delta p}\right)} \stackrel{d}{=} \bar{I}_{1}^{U},
$$

since a marginal unit of investment raises the NPV by $p_{h} R-1<p_{h}\left(\frac{B_{0}+B_{s}}{\Delta p}\right)$. Rewriting Eq. (4) as $p_{h}\left(\frac{B_{0}+B_{s}}{\Delta p}\right) I_{1}^{U}-(A+P) \leq\left(p_{h} R-1\right) I_{1}^{U}$ implies that $\mathrm{HQ}_{f}$ 's (expected) net agency rent, i.e., the difference between the (expected) gross agency rent $\mathrm{HQ}{ }_{f}$ receives for incentive purposes, $p_{h}\left(\frac{B_{0}+B_{s}}{\Delta p}\right) I_{1}^{U}$, and its financial input, $(A+P)$, must be inferior to the project's (expected) NPV. The resources $(A+P)$ help decrease the net rent so that the level of investment and the external financing capacity of the firm, $I_{1}^{U}-(A+P)$, increase in $(A+P)$. They decrease with the severity of moral hazard. Eq. (4) further shows that the two moral hazard problems algebraically add up within a U-form structure. ${ }^{5}$ Things will be different under the M-form.

$\mathrm{HQ}_{f}$ earns the project's NPV since investors just break even, which ensures that its participation constraint, Eq. (2), is verified. ${ }^{6}$ The NPV increases in $I_{1}^{U}$. Thus, the optimal level of investment satisfies Eq. (4) with equality.

Now consider project 2. It is in the interest of $\mathrm{HQ}_{f}$ to sell the project which cannot be realized internally since the product of the sale increases the amount of initial resources $\mathrm{HQ}_{f}$ can contribute to project 1 , and thus the investment capacity as appears in Eq. (4). Again, every party earns a zero-payoff because of limited liability when project 2 fails. $I_{2}^{U}$ denotes the level of investment in project 2 and $D_{2}^{U}$ the investors' revenue in case of success. The objective of $\mathrm{HQ}_{f}$ is to maximize the price paid up-front by $F$ to acquire project $2 .^{7}$ The following constraints must be respected. First, the headquarters of $F\left(\mathrm{HQ}_{F}\right)$ must be induced to work, which leads, by analogy with Eq. (1), it leads to Eq. (5). Next, $\mathrm{HQ}_{F}$ must recoup the resources $\alpha A$ it invested: Its participation constraint, given by Eq. (6), reflects that $\mathrm{HQ}_{F}$ paid $P$ to buy project 2, and further contributes $(\alpha A-P)$ to the investment in project 2 . Finally, the investors' participation constraint, given by Eq. (7), ensures that they recoup their funds, $I_{2}^{U}-(\alpha A-P)$.

To summarize, $\mathrm{HQ}_{f}$ solves the following program:

$$
\begin{array}{ll} 
& \max _{I_{2}^{U}, D_{2}^{U}} P \\
\text { s.t. } & p_{h}\left(R I_{2}^{U}-D_{2}^{U}\right) \geq p_{l}\left(R I_{2}^{U}-D_{2}^{U}\right)+\left(B_{O}+B_{S}\right) I_{2}^{U} \\
& p_{h}\left(R I_{2}^{U}-D_{2}^{U}\right) \geq(\alpha A-P)+P \\
& p_{h} D_{2}^{U} \geq I_{2}^{U}-(\alpha A-P) .
\end{array}
$$

Again, the investors' participation constraint optimally binds since investors are competitive and not subject to moral hazard: $D_{2}^{U}=\frac{I_{2}^{U}-(\alpha A-P)}{p_{h}}$. Substituting $D_{2}^{U}$ into the incentive compatibility constraint and the participation constraint of $\mathrm{HQ}_{F}$ leads to $P \leq \alpha A-\left[1-p_{h}\left(R-\frac{B_{0}+B_{s}}{\Delta p}\right)\right] I_{2}^{U}$ and $P \leq\left(p_{h} R-1\right) I_{2}^{U}$, respectively. Observe that raising $I_{2}^{U}$ relaxes the participation constraint since $p_{h} R-1>0-$ which allows $\mathrm{HQ}_{f}$ to increase $P$ - but has the opposite effect on the incentive constraint since $1-p_{h}\left(R-\frac{B_{0}+B_{s}}{\Delta p}\right)>0$. Thus, $P$ is maximized when the two constraints bind, which implies that $I_{2}^{U}=\frac{\alpha A}{p_{h}\left(\frac{B_{0}+B_{s}}{\Delta p}\right)} \stackrel{d}{=} \bar{I} \frac{U}{2}$. Accordingly, $\mathrm{HQ}_{f}$ receives

$$
P=\frac{p_{h} R-1}{p_{h}\left(\frac{B_{0}+B_{s}}{\Delta p}\right)} \alpha A>0
$$

\footnotetext{
${ }^{5}$ Hence, it extends Tirole's (2005) result that the financing capacity of a firm decreases with the severity of the one-dimension moral hazard problem he considers to the case of a U-form structure where moral hazard has two dimensions.

${ }^{6}$ For the sake of brevity, we do not check in the text that limited liability is respected when the project succeeds. Since HQ $f$ receives a zero-revenue when project 1 fails, the fact that its participation constraint is overall satisfied ensures that $\mathrm{HQ}_{f}$ receives a positive revenue when the project succeeds. This remark applies to the investors, and to project 2 as well.

7 Another interpretation would be that the headquarters sells the second project to an engineer as part as a corporate venture capital program. See Section 4 .
} 
and $\mathrm{HQ}_{F}$ makes no profit. Observe that the price $\mathrm{HQ}_{F}$ pays up-front to acquire project 2 limits its future financial contribution to the project, which raises $D_{2}^{U}$, for a given level of $I_{2}^{U}$. In turn, it reduces the fraction of the cash-flows $\mathrm{HQ}_{F}$ receives when project 2 succeeds, which weakens incentives, diminishes profits, and thus imposes an upper limit on $P$. Since $P<\alpha A$, the positive impact of the additional resources derived by $\mathrm{HQ}_{f}$ from the sale of project 2 on the amount that can be invested in project 1 is limited.

Proposition 1 characterizes the overall gain of $\mathrm{HQ}_{f}$. It corresponds to the product of the NPV per unit of investment and the investment realized in project 1 given by Eq. (4), where $P$ is determined in Eq. (8).

Proposition 1. When $\mathrm{HQ}_{f}$ keeps $f$ under the $U$-form, it earns

$$
\left(p_{h} R-1\right)\left[\frac{1+\alpha \frac{p_{h} R-1}{p_{h}\left(\frac{B_{0}+B_{S}}{\Delta p}\right)}}{1-p_{h}\left(R-\frac{B_{0}+B_{s}}{\Delta p}\right)}\right] A .
$$

We now consider the case where the two projects are realized under the same roof.

\subsection{Adopting the M-form structure and realizing the two projects}

Undertaking the two projects internally forces $\mathrm{HQ}_{f}$ to alter the firm's organizational structure: $\mathrm{HQ}_{f}$ delegates operational decision making to division $j$ (with $j=1,2$ ) as far as project $j$ is concerned. Without loss of generality, let division 1 be former $\mathrm{U}$-form independent firm $F$ with assets $\alpha A$ (but without a project) that $\mathrm{HQ}_{f}$ acquires and integrates within an enlarged company, $M$. Division 2 is created from scratch. We later compare this solution with the alternative which consists in creating the two divisions from scratch. ${ }^{8}$

Again, limited liability imposes that all parties receive a zero-revenue when both projects fail. $D^{M}$ denotes the investors' revenue when the two projects succeed, $d_{j}^{M}$ the investors' revenue when only project $j$ succeeds, $r_{j}$ division's $j$ revenue when $j$ 's project succeeds, and $I_{j}^{M}$ the investment in $j$.

$\mathrm{HQ}_{f}$ maximizes its net revenue. Here, the latter is equal to $p_{h}^{2}\left[\sum\left(R I_{j}^{M}-r_{j}\right)-D^{M}\right]+p_{h}\left(1-p_{h}\right) \sum\left(R I_{j}^{M}-r_{j}-d_{j}^{M}\right)$, i.e., the expected cashflows of the projects net of any payments to the investors and the divisions. The following constraints must be satisfied.

First, divisions should face proper incentives. Observe that allocating $r_{j}>0$ to $j$ whose project succeeds whatever the result of the other division fosters $j$ 's incentives since projects are independent. Also, punishing $j$ by setting $r_{j}=0$ when $j$ 's project fails whatever the result of the other division fosters $j$ 's incentives. Thus, $j$ is induced to exert the effort that is necessary to make an adequate operational decision if Eq. (10) is verified. Division 1 and division 2 contribute $\alpha A$ and 0 , respectively, to their project so that their participation constraints are summarized by Eq. (11).

$\mathrm{Next}, \mathrm{HQ}_{f}$ must perform the level of investigation effort compatible with proper decision making. It requires that its revenue should be larger when it works on the two projects than when it shirks on the two projects. It writes $p_{h}^{2} W+2 p_{h}\left(1-p_{h}\right) w \geq p_{l}^{2} W+$ $2 p_{l}\left(1-p_{l}\right) w+B_{s}\left(I_{1}^{M}+I_{2}^{M}\right)$, where $W$ and $w$ denote $H Q_{f}$ 's revenue when two projects succeed and one project succeeds, respectively. Setting $w=0$ relaxes the constraint since $p_{h}>p_{l} \geq \frac{1}{2}$. The intuition is that a high probability of success of a project commands to be particularly severe for incentive reasons in case of failure. Setting $w=0$ also increases the cash-flows the investors receive when one out of the two projects fails. Replacing $W$ by $R\left(I_{1}^{M}+I_{2}^{M}\right)-\left(r_{1}+r_{2}\right)-D^{M}$ and manipulating leads to HQ $f$ 's incentive compatibility constraint, summarized by Eq. (12). ${ }^{9} \mathrm{HQ}_{f}$ 's participation constraint, given by Eq. (12), takes into account that $\mathrm{HQ}_{f}$ 's contribution to the projects is $A$, and that $w=0$. HQ $f$ 's reduced objective function derives from Eq. (13).

Finally, the investors' participation constraint, Eq. (14), takes into account that the investors provide $\left(I_{1}^{M}+I_{2}^{M}\right)-A(1+\alpha)$ to the firm.

To summarize, $\mathrm{HQ}_{f}$ solves the following program:

$$
\begin{array}{ll} 
& \max ^{M}, p_{h}^{2}\left[R\left(I_{1}^{M}+I_{2}^{M}\right)-\left(r_{1}+r_{2}\right)-D^{M}\right] \\
& D^{M}, d_{1}^{M}, d_{2}^{M} \\
\text { s.t. } & p_{h} r_{1} \geq p_{l} r_{1}+B_{0} I_{1}^{M} ; \quad p_{h} r_{2} \geq p_{l} r_{2}+B_{0} I_{2}^{M} \\
& p_{h} r_{1} \geq \alpha A ; \quad p_{h} r_{2} \geq 0 \\
& \left(p_{h}+p_{l}\right) \Delta p\left[R\left(I_{1}^{M}+I_{2}^{M}\right)-\left(r_{1}+r_{2}\right)-D^{M}\right] \geq B_{S}\left(I_{1}^{M}+I_{2}^{M}\right) \\
& p_{h}^{2}\left[R\left(I_{1}^{M}+I_{2}^{M}\right)-\left(r_{1}+r_{2}\right)-D^{M}\right] \geq A \\
& p_{\mathrm{h}}^{2} D^{M}+p_{h}\left(1-p_{h}\right)\left(d_{1}^{M}+d_{2}^{M}\right) \geq\left(I_{1}^{M}+I_{2}^{M}\right)-A(1+\alpha) .
\end{array}
$$

The investors' participation constraint optimally binds since investors are competitive and not subject to moral hazard.

\footnotetext{
${ }^{8}$ If a second U-form independent unit with resources but without a project existed, the M-form could also benefit from these resources by integrating that unit. However, business life shows that this scenario, i.e., integrating independent units several at a time, is quite unrealistic since integration is difficult to handle because of, e.g., differences in firms' culture (e.g., Weber et al., 1996). The results for this case are available from the author upon request.

${ }^{9}$ To be complete, $\mathrm{HQ}_{f}$ must also be induced to work on the two projects rather than on $j$ 's project. This condition writes in its extensive form as $p_{h}^{2} W+2 p_{h}\left(1-p_{h}\right)$ $w \geq p_{h} p_{l} W+\left[p_{l}\left(1-p_{h}\right)+\left(1-p_{l}\right) p_{h}\right] w+B_{s} I_{j}^{M}$, and reduces to $p_{h} W-\left(2 p_{h}-1\right) w \geq \frac{B_{s} l_{j}^{M}}{\Delta p}$. Condition (12) writes in its reduced form as $\left(p_{h}+p_{l}\right) W-2\left(p_{h}+p_{l}-1\right) w \geq \frac{B_{s}\left(I_{1}^{M}+l_{2}^{M}\right)}{\Delta p}$. Setting $w=0$ relaxes both constraints since $p_{h}>p_{l} \geq \frac{1}{2}$. Observe that inducing $\mathrm{HQ}_{f}$ to work on two projects rather than on zero project is the most stringent constraint if investments in the two projects are not too dissimilar, i.e., $\frac{p_{l}}{p_{h}} \leq \frac{I_{1}^{M}}{M_{2}^{M}} \leq \frac{p_{h}}{p_{l}}$. This pattern is shown below to be optimal.
} 
The divisions' incentive compatibility constraints optimally bind. To see this, suppose $j$ 's does not. Let $r_{j}$ be fixed. Then, raising $I_{j}^{M}$ while keeping $r_{j}$ constant and still satisfying Eq. (10) is possible. Raising $I_{j}^{M}$ has no impact on Eq. (11). It relaxes Eq. (12). To see this, (i) substitute $d_{j}^{M}=R I_{j}^{M}-r_{j}$ into Eq. (14) satisfied with equality, and the resulting expression of $D^{M}$ into Eq. (12), which leads to $\left[p_{h}\left(R-\frac{(1-\lambda) B_{s}}{\Delta p}\right)-1\right]\left(I_{1}^{M}+I_{2}^{M}\right)-p_{h}\left(r_{1}+r_{2}\right)+A(1+\alpha) \geq 0$ where $\lambda \stackrel{d}{=} \frac{p_{l}}{p_{l}+p_{h}}$, and (ii) recall that $p_{h}\left(R-\frac{B_{s}}{\Delta p}\right)-1>0$. Raising $I_{j}^{M}$ also increases $\mathrm{HQ}_{f}$ 's revenue, and thus relaxes Eq. (13). To see this, substitute $D^{M}$ into $\mathrm{HQ}_{f}$ 's revenue function, which leads to $\left(p_{h} R-1\right)\left(I_{1}^{M}+i_{2}^{M}\right)-$ $p_{h}\left(r_{1}+r_{2}\right)+\alpha A \geq 0$ and recall that $p_{h} R-1 \geq 0$. Hence, $r_{j}=\frac{B_{0} I_{j}^{M}}{\Delta p}$.

Substituting $r_{j}$ into the divisions' participation constraints shows that a minimum level of investment exists at the division level: $I_{1}^{M} \geq \frac{\alpha A}{p_{h} \frac{B_{0}}{A p}}$ and $I_{2}^{M} \geq 0$. Substituting $r_{j}$ into $\mathrm{HQ}_{f}$ 's incentive compatibility constraint shows that an upper limit also exists:

$$
I_{1}^{M}+I_{2}^{M} \leq \frac{(1+\alpha) A}{1-p_{h}\left(R-\frac{B_{0}+(1-\lambda) B_{s}}{\Delta p}\right)} \stackrel{d}{=} \bar{I}^{M} .
$$

The upper and lower limits are compatible. Eq. (15) indicates that the maximum level of investment and the external financing capacity of the multidivisional firm increase in $A$ and $\alpha$, and decrease with the severity of moral hazard as in the U-form case. However, comparing $\bar{I}^{M}$ to

$$
\bar{I}^{U} \stackrel{d}{=} \frac{\left[1+\alpha \frac{p_{h} R-1}{p_{h}\left(\frac{B_{0}+B_{s}}{\Delta p}\right)}\right] A}{1-p_{h}\left(R-\frac{B_{0}+B_{s}}{\Delta p}\right)},
$$

obtained by combining Eqs. (4) and (8), shows two major differences. First, the lower denominator of $\bar{I}^{M}$, as evidenced by the impact of $\lambda>0$, reflects the possibility of $M$ to reimburse investors with the cash-flows of a successful division if the other division makes losses, which relaxes credit constraints. This pattern is referred to as cross-pledging in the literature. ${ }^{10}$ The fact that crosspledging increases the financing capacity of an M-form even when moral hazard has two dimensions and is double-sided extends the result of Lewellen (1971). Intuitively, the full benefit of cross-pledging is obtained when investments in the two projects are quite similar. A contrario, investing in only one project would cancel this effect. Also, the full benefit of cross-pledging is obtained when projects are independent. This pattern is consistent with empirical evidence that conglomerate mergers are very strongly motivated by the objective of enjoying financial synergies (Walter and Barney, 1990). Second, the numerator of $\bar{I}^{M}$ is larger than the numerator of $\bar{I}^{U}$ since the price paid by $F$ to acquire project 2 - hence the additional wealth for $\mathrm{HQ}_{f}-$ is strictly lower than $\alpha A$ for incentive purposes. These two reasons imply that investment is higher under the M-form than under the U-form. We refer to this property as the "investment capacity effect".

Investing $\bar{I}^{M}$ is optimal for $\mathrm{HQ}_{f}$ since its revenue increases in the level of investment. ${ }^{11}$ To see this, combine $d_{j}^{M}=R I_{j}^{M}-r_{j}$, Eqs. $(10)$ and (14) both satisfied with equality with Eq. (13), and recall that $p_{h} \frac{B_{0}}{\Delta p}<p_{h} R-1$. It implies that acquiring the firm endowed with financial resources but no project is preferred to setting up the two divisions from scratch. According to Eq. (15), $\bar{I}^{M}$ is such that

$$
\left[p_{h} \frac{(1-\lambda) B_{S} \bar{I}^{M}}{\Delta p}-A\right]+\left[p_{h} \frac{B_{0} \bar{I}^{M}}{\Delta p}-\alpha A\right]=\left(p_{h} R-1\right) \bar{I}^{M}
$$

In words, the sum of $\mathrm{HQ}_{f}$ 's net agency rent and the divisions' aggregate net agency rents is optimally equal to the NPV. Observe that the divisions' aggregate net rents are strictly lower than the NPV since $p_{h} \frac{B_{0}}{\Delta p}<p_{h} R-1$. Thus, HQ $f$ 's net rent is strictly positive when Eq. (17) holds, which ensures that $\mathrm{HQ}_{f}$ 's participation constraint, Eq. (13), is satisfied. ${ }^{12}$ Symmetrically, observe that $\mathrm{HQ}_{f}$ 's net rent is strictly lower than the NPV since $p_{h} \frac{B_{s}}{\Delta p}<p_{h} R-1$. Thus, whatever the level of the divisions' input, the aggregate net rents of the divisions are strictly positive when Eq. (17) holds, i.e., at the optimum. In other words, $\mathrm{HQ}_{f}$ prefers leaving a rent to the divisions and investing more to making them just recoup the funds they contributed to the projects. It is important to remark that it is not the addition of another source of moral hazard that drives the divisions' strictly positive net rents - indeed there is no additional source of moral hazard. Rather, it is the fact that the two sources of moral hazard (strategic and operational) interact in a different way as compared to the case of a Uform. The "rent effect" implies that $\mathrm{HQ}_{f}$ does not earn the whole NPV of the two projects. Proposition 2 characterizes its revenue.

\footnotetext{
${ }^{10}$ In this paper, we normalize to one the number of projects that can be realized under the U-form, so that the latter does not benefit from cross-pledging. In practice, U-forms can accommodate several projects. Our assumption is simply meant to reflect that the extent of cross-pledging is larger under M-forms since the latter can accommodate more projects than U-forms.

${ }^{11}$ Since $p_{h} R-1 \geq 0$, each unit of investment raises the NPV. Thus, $T^{M}$ not only maximizes $\mathrm{HQ}_{f}$ 's revenue but also the NPV.

12 For the sake of brevity, we do not check in the text that limited liability is respected. The investors' revenue when $j^{\prime}$ s project succeeds is $d_{j}^{M}=\left(R-\frac{B_{0}}{\Delta p}\right) I_{j}^{M}>0$. Their revenue when two projects succeed is $D^{M}=\left(R-\frac{B_{0}+\frac{B_{s}}{p_{h}}+p_{l}}{\Delta p}\right)\left(I_{1}^{M}+I_{2}^{M}\right) \geq 0$ since $p_{l} \geq \frac{1}{2}$. Thus, the investors' limited liability is respected. Since the divisions receive a zero-revenue when their project fails, the fact that their participation constraint is overall satisfied ensures that they receive a positive revenue when their project succeeds, so that the sharing rule of the cash-flows also respects their limited liability. Finally, since $\mathrm{HQ}_{f}$ receives a zero-revenue if a project fails, the fact that its participation constraint is overall satisfied ensures that its revenue when the two projects succeed is positive, so that the sharing rule of the cashflows respects $\mathrm{HQ} f$ 's limited liability.
} 
Proposition 2. When $\mathrm{HQ}_{f}$ moves $f$ to the $M$-form, it earns

$$
\left[\frac{(1+\alpha)\left[p_{h} \frac{(1-\lambda) B_{s}}{\Delta p}\right]}{1-p_{h}\left(R-\frac{B_{0}+(1-\lambda) B_{s}}{\Delta p}\right)}-1\right] A \text {. }
$$

We consider the choice of organization $\mathrm{HQ}_{f}$ makes in the next section.

\section{Optimal organization}

Our objective in this section is twofold. First, we determine the organizational structure that HQ $f$ prefers. Next, we propose alternative interpretations of our basic framework. Throughout this section, we discuss the results and derive empirical implications.

\subsection{The headquarters' choice}

$\mathrm{HQ}_{f}$ faces the following trade-off. On the one hand, altering the structure of the firm in order to adopt the M-form increases profits: Whatever the organizational structure, the NPV per unit of investment is $p_{h} R-1$ but the level of investment is higher under the M-form. On the other hand, $\mathrm{HQ}_{f}$ must share the NPV with the divisions under the M-form. Its final choice depends on the magnitude of $B_{O}$ and $B_{s}$, and the resources $F$ is endowed with, measured by $\alpha$. This choice is detailed in the next proposition. Everything else being equal, we assume that $\mathrm{HQ}_{f}$ prefers running a company as large as possible.

Proposition 3. There exist a real number $\underline{B_{S}}$, and real-valued functions $\underline{B_{O}}\left(B_{S}\right), \overline{B_{O}}\left(B_{S}\right)$ and $\underline{\alpha}\left(B_{0}, B_{S}\right)$ such that:

(i) $\mathrm{HQ}_{f}$ moves $\mathrm{f}$ to the $\mathrm{M}$-form when

$$
\begin{aligned}
& B_{0} \leq \underline{B_{O}}\left(B_{S}\right), \\
& \underline{B_{0}}\left(B_{S}\right)<B_{O}<\overline{B_{O}}\left(B_{S}\right) \text { and } \alpha \geq \underline{\alpha}\left(B_{0}, B_{S}\right), \\
& B_{0} \geq \overline{B_{0}}\left(B_{S}\right), \alpha \geq \underline{\alpha}\left(B_{0}, B_{S}\right) \text { and } B_{S} \geq \underline{B_{S}} .
\end{aligned}
$$

(ii) Otherwise, $H Q_{f}$ keeps $f$ under the $U$-form.

The intuition for these results is the following. When operational moral hazard is low, i.e., $B_{0} \leq B_{0}$, it is optimal for $\mathrm{HQ}_{f}$ to have $f$ adopt an M-form since divisional net agency rents are small. Next, suppose that moral hazard pertaining to operational decisions is moderate, i.e., $B_{0}<B_{0}<\overline{B_{0}}$. Observe from Eqs. (9) and (18) that the derivative of the headquarters' revenue with respect to $\alpha$ is higher under the M-form than under the U-form. In other words, the financial resources of $F$ have more value for $\mathrm{HQ}_{f}$ inside an $\mathrm{M}$-form than inside a U-form. Thus, the M-form is all the more attractive as $F$ is endowed with large resources. If these resources are sufficient, i.e., $\alpha \geq \underline{\alpha}$, the investment capacity effect dominates the rent effect, and $\mathrm{HQ}_{f}$ modifies the structure of the company. If these resources are insufficient, $\mathrm{HQ}_{f}$ prefers to keep the firm under the U-form, and the firm does not grow. Finally, when operational moral hazard is pronounced, i.e., $B_{0} \geq \overline{B_{0}}$, either $B_{s}<B_{s}$ and $\mathrm{HQ}_{f}$ prefers running a U-form since its own rent is too small under the Mform, or $B_{s} \geq B_{s}$ and $\mathrm{HQ}_{f}$ faces the same trade-off as above.

We derive a couple of testable empirical implications from the above results. All else equal,

- The larger the resources of a firm without projects (e.g., characterized by a low market to book ratio), the more likely this firm will be the target of firms endowed with projects (e.g., characterized by a high market to book ratio), instead of the buyer of such projects. This implication allows us to characterize the circumstances under which "financial acquisitions", i.e., acquisitions of other companies in order to benefit from their cash resources, occur (see, e.g., Grinblatt and Titman, 2001, for a categorization of mergers and acquisitions).

- Controlling for $\alpha$, the size of projects realized internally should be larger than the size of projects realized externally (e.g., through a corporate venture capital program).Indeed, suppose that $\alpha=1$ so that financial endowments are comparable. The size of $f$, given by $\hat{I}_{1}^{U} \stackrel{d}{=} \frac{\left(1+\frac{p_{h} R-1}{p_{h}\left(\frac{B_{0}+B_{S}}{\Delta p}\right)}\right) A}{1-p_{h}\left(R-\frac{B_{O}+B_{S}}{\Delta p}\right)}$, is larger than the size of $F$, given by $\hat{I}_{2}^{U} \stackrel{d}{=} \frac{A}{p_{h}\left(\frac{B_{0}+B_{S}}{\Delta p}\right)}$. Corporate venture capital programs (e.g., by Intel, Microsoft, etc.) offer engineers the opportunity to set up their own firm based on an innovation they have discovered during their employment period. Suppose that laws protecting intellectual property prevent employees from stealing the innovation, i.e., they have to buy it from their current employer before establishing their own business. Reinterpreting our results along these lines suggests that these projects should be of smaller size than their counterparts realized internally.

- Controlling for $\alpha$, the size of the projects realized by M-form structures should be on average larger than the size of the projects realized by U-form structures.

Again, suppose that $\alpha=1$ and compare $\frac{\bar{I}^{M}}{2}=\frac{A}{1-p_{h}\left(R-\frac{B_{0}+(1-\lambda) B s}{\Delta p}\right)}$ to $\frac{\hat{I}_{1}^{U}+\hat{I}_{2}^{U}}{2}$. This result is reinforced by the fact that headquarters prefer to run M-forms if $\alpha$ is high enough. The evidence reported in Villalonga (2004) supports the implication. Simple computations 
show that the segments of single-segment firms are 1.8 times smaller than the segments of multisegment firms in terms of employment (2.2 times smaller in terms of assets), for firms included in the Compustat database. These results are robust to the various samples and databases considered in the paper even though the orders of magnitude slightly differ.

Proposition 4 details some comparative statics results.

Proposition 4. The M-form is:

(i) More attractive to $\mathrm{HQ}_{f}$ when, keeping $B_{0}+B_{s}$ constant, $B_{s}$ increases;

(ii) Less attractive to $H Q_{f}$ when $B_{0}$ increases.

The intuition for result (i) is the following. When the sum of the intensities of the moral hazard problems is kept constant but $B_{S}$ increases, $\mathrm{HQ}_{f}$ obtains a higher rent per unit of investment at the expense of the divisions under the M-form, whereas its rent per unit of investment under the U-form is unaffected. Moreover, the investment capacity and the profits are unaffected under the U-form, whereas they increase under the M-form, thanks to $\lambda$. One implication of this result is that one should observe firms moving from the unitary to the multidivisional structure when they face more uncertainty regarding strategic issues and less uncertainty regarding operational issues. To put it into perspective, note that the M-form became very popular in the United States after the end of World War II, once the biggest American firms mastered new technologies but faced strategic challenges on how to diversify their activity.

A higher $B_{O}$ makes the M-form a less attractive alternative to $\mathrm{HQ}_{f}$ since the investment capacity is reduced and the divisions' rents increase. Result (ii) is consistent with the idea that centralization (here, keeping the U-form) is an increasing function of the control cost of transferring decisions from the headquarters to the divisions (see, e.g., Christie et al., 2003). ${ }^{13}$ More generally, a higher $B_{O}$ can justify corporate asset downsizing (asset sales, division spinoffs, etc. ${ }^{14}$ ) for existing M-form companies, or even, make the U-form an attractive alternative for such firms.

We now consider alternative interpretations of our basic framework.

\subsection{Other interpretations}

We slightly alter our initial assumptions to allow for other interpretations of our basic framework. Suppose that $X$ - an entrepreneur or a firm - has only one project and owns financial assets $A$. $Y$ - another firm or a financial intermediary - has no project but owns $\alpha$ A. Two tasks must be performed in order to achieve the project. Either task 1 and task 2 are performed by $X$, or task 1 is performed by $X$ while task 2 is performed by $Y$. Unless otherwise stated, our initial set of assumptions applies.

\subsubsection{Acquisitions}

Suppose that firm $X$ considers acquiring $Y$, a firm that used to commercialize the same product or service as $X$, but is currently lacking the financial muscle to operate as a stand-alone. The cost of effort or private benefit pertaining to task 1 (respectively, task 2 ) is $B_{1}$ (respectively, $B_{2}$ ). Without loss of generality let $B_{1}>B_{2}$. Pooling their resources and working together on production would allow $X$ to raise more external funds so as to operate a larger plant than $X$ could operate separately. ${ }^{15}$ This pattern is consistent with long-standing empirical evidence that horizontal mergers try to exploit financial synergies (Chatterjee, 1986; Walter and Barney, 1990). Without $Y, X$ earns $\frac{\left(p_{h} R-1\right) A}{1-p_{h}\left(R-\frac{B_{1}+B_{2}}{\Delta p}\right)}$, i.e., the product of $p_{h} R-1$, the NPV per unit of investment, and the investment, $\frac{A}{1-p_{h}\left(R-\frac{B_{1}+B_{2}}{\Delta p}\right)}$. If acquiring $Y$, profits are larger since investment is multiplied by $(1+\alpha)$. However, $X$ has to share these profits with $Y$ for incentive purposes, resulting in a revenue of $\left[\frac{(1+\alpha) p_{h 1}^{B_{1}}}{1-p_{h}\left(R-\frac{B_{1}+B_{2}}{A p}\right)}-1\right] A$. Thus, it is worth acquiring $Y$ if $Y$ is rich enough, which translates, here, into $\alpha \geq \frac{B_{2}}{B_{1}}$.

\subsubsection{Joint venture}

Suppose now that $Y$ has a comparative advantage in performing task 2 in the sense that its cost of effort is lower or its reputation is more established: The private benefit is $B_{2}$ if task 2 is performed by $X$, and $\delta B_{2}$ with $\delta<1$ if task 2 is performed by $Y$. For example, let $X$ be a French firm willing to set foot on the Russian automobile market. $Y$ is a Russian firm that perfectly knows its national market. $X$ and $Y$ could form a joint venture: $X$ would produce cars and $Y$ would use its network to commercialize them. Again, it is worth collaborating with $Y$ (i.e., benefiting from $Y$ 's expertise to increase the NPV per unit investment, which in turn raises investment capacity and thus total profits) provided that $Y$ is rich enough, i.e., $\alpha \geq \frac{\delta B_{2}}{B_{1}}$. Of course, setting up a joint venture is all the more desirable as the comparative advantage of $Y$ in performing task 2 is significant, i.e., $\delta$ is low.

\subsubsection{Venture capital}

Finally, let $X$ be an entrepreneur and $Y$ a venture capitalist (VC) or a business angel. Suppose that task 2 is no longer necessary to realize the project. However, if performed by $Y$, it increases the cash-flows in case of success of the project by $\Delta R$. This assumption is meant to reflect that the VC advises the entrepreneur (regarding, e.g., the firm's strategy, its marketing policy, the recruiting of key personnel), and helps the latter securing funds from other investors (e.g., banks or other VCs when the VC under consideration acts as the leader of a syndicate). Further assume that the VC's help is valuable only to the extent that the entrepreneur works. Contrary to the maintained hypothesis, and consistent with the fact that only task 1 is necessary to realize the project, let $p_{h}\left(R-\frac{B_{1}}{\Delta p}\right)-1<0$ to

\footnotetext{
${ }^{13}$ An increase in $B_{S}$ has no clear-cut implications. On the one hand, it increases the fraction of the profits that HQ $f$ receives under the M-form. On the other hand, it decreases the investment capacity, and in turn the profits to be shared.

14 For recent literature, see, e.g., Denis and Shome (2005), and Ahn and Walker (2007).

15 Observe that if $Y$ stopped production, $Y$ would be equivalent to a financier and its financial input would not allow $X$ to increase the total amount borrowed.
} 
have informational frictions impose a limit on the level of investment. By involving the VC in the project, the entrepreneur increases the NPV per unit of investment, and thus the investment capacity and the profits. However, since the entrepreneur must share these profits with the VC for incentive purposes, it is worth addressing the latter if and only if $\alpha \geq \frac{B_{2}-\Delta p \Delta R}{B_{1}-\frac{\Delta p}{p_{h}}\left(p_{h} R-1\right)}$. In words, the VC's financial contribution to the project must be sufficient. Naturally, the above threshold decreases in $\delta R$, the VC's incremental ability. Other theoretical papers model the desirability of addressing VCs. By assuming that the project's size is fixed and the VC's wealth is unlimited, Casamatta (2003) does not leave room for outside investors. In contrast, the latter are valuable here, which is consistent with the observation that an active VC is generally not the sole investor to put money in a start-up company. The same remark applies to Inderst and Müller (2004), Renucci (2000), Repullo and Suarez (2004), and Schmidt (2003), since the project's size is also assumed to be fixed in these papers.

To summarize, the trade-off between increasing investment capacity and profits, and sharing these profits, that we identified in the M-form versus U-form case also applies to other situations.

\section{Concluding remarks}

This paper shows that the organizational structure of a firm impacts on its financing capacity, its profits, and how these profits are shared. The advantage of the moving to the multidivisional structure for the headquarters of a unitary structure concerned about overload is the investment capacity effect which raises profits. The drawback of moving to the multidivisional structure is the rent effect, i.e., the fact that delegating decisions to divisions implies to leave them agency rents whatever their financial contribution to their project. Thus, overload does not automatically imply adopting a multidivisional structure. The same trade-off between raising investment capacity and profits, and sharing these profits can explain the choice of firms to engage in acquisitions or form joint ventures, and of entrepreneurs to address venture capitalists. The understanding of other institutional arrangements such as matrix-type organizations which exhibit a complex nexus of decision makers is left for future research. Recently, the efficiency of these organizations has been argued by practitioners and the matrix form abandoned by a number of firms. A possible explanation, consistent with our results, is that this kind of structure involves too large and too many agency rents. We also leave for future research the design of an optimal organizational structure based on incentives problems in the spirit of the recent literature on the design of institutions that focuses on information processing (e.g., Radner, 1992; Radner and Van Zandt, 1992; Van Zandt, 1998), the organization of knowledge acquisition in production (Garicano, 2000), or more generally, coordination (e.g., Crémer, 1980; Qian et al., 2006). A force of this literature is that organizational structures are usually obtained rather than assumed.

\section{Appendix A}

Proof of Proposition 3. $\mathrm{HQ}_{f}$ prefers the M-form when the revenue given by Eq. (9) is lower than the revenue given by Eq. (18), which reduces to

$$
\alpha P_{\mathrm{LHS}}\left(B_{0}\right) \leq\left(p_{h} \frac{B_{O}+B_{S}}{\Delta p}\right) \times P_{\mathrm{RHS}}\left(B_{O}\right),
$$

where

$$
P_{\mathrm{RHS}}\left(B_{0}\right) \stackrel{d}{=}-\left(p_{h} \frac{B_{O}}{\Delta p}\right)^{2}+\left[p_{h}\left(R-\frac{B_{S}}{\Delta p}\right)-1\right]\left(p_{h} \frac{B_{O}}{\Delta p}\right)+\left(p_{h} R-1\right) p_{h} \frac{\lambda B_{S}}{\Delta p}
$$

and

$$
\begin{aligned}
P_{\mathrm{LHS}}\left(B_{0}\right) \stackrel{d}{=} & -p_{h} \frac{(1-\lambda) B_{S}}{\Delta p}\left(p_{h} \frac{B_{O}}{\Delta p}\right)^{2}+\left[\left(p_{h} R-1\right)^{2}-(1-\lambda)\left(p_{h} \frac{B_{S}}{\Delta p}\right)^{2}+p_{h} \frac{(1-\lambda) B_{s}}{\Delta p}\left[p_{h}\left(R-\frac{B_{S}}{\Delta p}\right)-1\right]\right]\left(p_{h} \frac{B_{O}}{\Delta p}\right) \\
& -\left[\left(p_{h} R-1\right)^{2}-(1-\lambda)\left(p_{h} \frac{B_{S}}{\Delta p}\right)^{2}\right]\left[p_{h}\left(R-\frac{B_{S}}{\Delta p}\right)-1\right]-\left(p_{h} R-1\right)^{2} p_{h} \frac{\lambda B_{S}}{\Delta p} .
\end{aligned}
$$

We have $P_{\mathrm{RHS}} \geq 0$ when $B_{O} \leq \underline{B}_{O}\left(B_{S}\right)$, where $\underline{B}_{O}\left(B_{S}\right) \stackrel{d}{=} \frac{p_{h}\left(R-\frac{B_{S}}{d p}\right)-1+\sqrt{\left[p_{h}\left(R-\frac{B_{s}}{d p}\right)-1\right]^{2}+4\left(p_{h} R-1\right) p_{h} \frac{\lambda B_{s}}{d p}}}{2\left(\frac{p_{h}}{d p}\right)}$. $P_{\mathrm{RHS}}<0$ when $B_{O}>\underline{B}_{O}\left(B_{S}\right)$. To show this, we use (i) the signs of the coefficients of $P_{\text {RHS }}$ which imply that (ii) $P_{\text {RHS }}$ always has two distinct roots and that (iii) the lower root is negative, and (iv) the fact that the upper root verifies $p_{h} R-1>p_{h} \frac{B_{0}}{\Delta p}>p_{h}\left(R-\frac{(1-\lambda) B_{s}}{\Delta p}\right)-1$.

We have $P_{\mathrm{LHS}} \geq 0$ when $B_{S}<\left(p_{h} R-1\right) \frac{2 \Delta p}{p_{h}(1+\sqrt{5})} \stackrel{d}{=} \underline{B}_{S}$ and $B_{O} \geq \bar{B}_{O}\left(B_{S}\right)$, where $\bar{B}_{O}\left(B_{S}\right)$, derived from the lower root of $P_{\mathrm{LHS}}$, is equal to

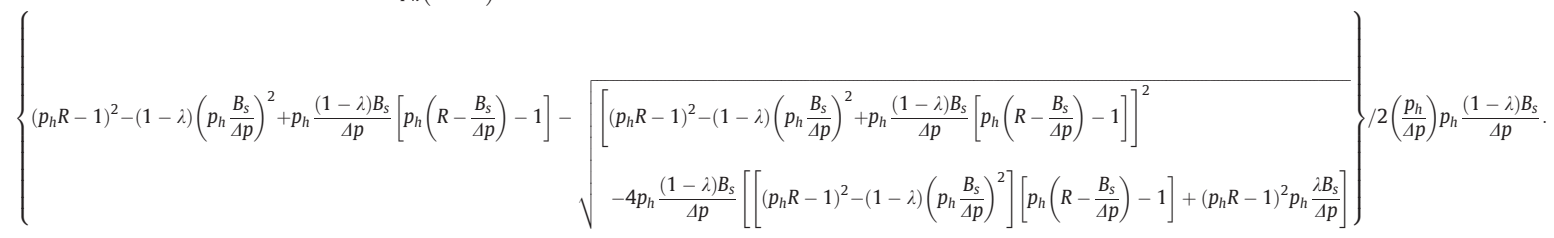

Besides, $P_{\mathrm{LHS}}<0$ when $B_{O}<\bar{B}_{O}\left(B_{S}\right)$ and $B_{S}<B_{S}$, or when $B_{S} \geq B_{S}$. To show this, we use: (i) the signs of the coefficients of $P_{\mathrm{LHS}}$; (ii) the fact that if $B_{S}<\frac{\Delta p\left(p_{h} R-1\right)}{p_{h}(1-\lambda+2 \sqrt{\lambda(1-\lambda)})} \stackrel{d}{=} \bar{B}_{S}$ (with $\bar{B}_{S}>\underline{B_{S}}$ ), $P_{\text {LHS }}$ has two positive and distinct roots, with the upper root not satisfying 
$p_{h} \frac{B_{0}}{\Delta p}<p_{h} R-1$, and the lower root satisfying $p_{h}\left(R-\frac{(1-\lambda) B_{s}}{\Delta p}\right)-1<p_{h} \frac{B_{0}}{\Delta p} \quad \forall B_{S}$, and $p_{h} \frac{B_{0}}{\Delta p}<p_{h} R-1$ when $B_{S}<B_{S}$; (iii) the fact that if $B_{s} \geq \bar{B}_{s}$, which is compatible with $p_{h} \frac{B_{s}}{\Delta p}<p_{h} R-1, P_{\text {LHS }}$ has at most one root which does not satisfy $p_{h} \frac{B_{0}}{\Delta p}<p_{h} R-1$.

Assume that everything else equal, the headquarters prefers running the largest possible company. First, let us distinguish between two cases.

Case 1. $B_{S}<B_{S}$. Comparing $\underline{B}_{0}\left(B_{S}\right)$ and $\overline{B_{0}}\left(B_{S}\right)$ shows that $\overline{B_{0}}\left(B_{S}\right)>\underline{B}_{0}\left(B_{S}\right)$. When $B_{0} \geq \overline{B_{0}}\left(B_{S}\right)$, Eq. (19) is never verified since $P_{\mathrm{LHS}} \geq 0$ and $P_{\mathrm{RHS}}<0$. When $\underline{B}_{O}\left(B_{S}\right)<\bar{B}_{O}<\overline{B_{O}}\left(B_{S}\right)$, Eq. (19) is verified if $\alpha \geq \frac{P_{\mathrm{RHS}}}{P_{\mathrm{LHS}}}\left(p_{h} \frac{B_{O}+B_{s}}{\Delta p}\right) \stackrel{d}{=} \underline{\alpha}\left(B_{O}, B_{S}\right)$, with $\underline{\alpha}\left(B_{O}, B_{S}\right)>0$ since $P_{\mathrm{LHS}}<0$ and $P_{\mathrm{RHS}}<0$. When $B_{O} \leq \underline{B}_{O}\left(B_{S}\right)$, Eq. (19) is always verified since $P_{\mathrm{LHS}}<0$ and $P_{\mathrm{RHS}} \geq 0$.

Case 2. $B_{S} \geq \underline{B}_{S}$. When $B_{O}>\underline{B}_{0}\left(B_{S}\right)$, Eq. (19) is verified if $\alpha \geq \underline{\alpha}\left(B_{O}, B_{S}\right)$. When $B_{O} \leq \underline{B}_{O}\left(B_{S}\right)$, Eq. (19) is always verified since $P_{\mathrm{LHS}}<0$ and $P_{\mathrm{RHS}} \geq 0$.

Finally, let us summarize these results as: $\mathrm{HQ}_{f}$ moves the firm to the M-form when (i) $B_{0} \leq B_{0}\left(B_{S}\right),\left(\right.$ ii) $B_{O}\left(B_{S}\right)<B_{O}<\overline{B_{0}}\left(B_{S}\right)$ and $\alpha \geq \underline{\alpha}\left(B_{0}, B_{s}\right)$, and (iii) $B_{0} \geq \overline{B_{0}}\left(B_{s}\right), \alpha \geq \underline{\alpha}\left(B_{s}, B_{0}\right)$ and $B_{s} \geq \underline{B_{s}}$. Otherwise, HQ ${ }_{f}$ keeps the U-form structure of the firm. It establishes Proposition 3.

\section{References}

Aggarwal, R.K., Samwick, A.A., 2006. Empire builders and shirkers: investment, firm performance, and managerial incentives. Journal of Corporate Finance 12, 489-515.

Aghion, P., Tirole, J., 1995. Some implications of growth for the organizational form and ownership structure. European Economic Review 39 , $440-459$.

Ahn, S., Denis, D.J., 2004. Internal capital markets and investment policy: evidence from corporate spin-offs. Journal of Financial Economics 71, 489-516.

Ahn, S., Walker, M.D., 2007. Corporate governance and the spinoff decision. Journal of Corporate Finance 13, 76-93.

Amihud, Y., Lev, B., 1981. Risk reduction as a managerial motive for conglomerate mergers. Bell Journal of Economics 12, 605-617.

Arrow, K., 1974. The Limits of Organization. Norton, New York.

Berkovitch, E., Israel, R., Tolkowsky, E., 2006. The boundaries of the firm: the choice between stand-alone and integrated firms. Journal of Economics and Management Strategy 15, 821-851.

Brusco, S., Panunzi, F., 2005. Reallocation of corporate resources and managerial incentives in internal capital markets. European Economic Review 49, 659-681. Casamatta, C., 2003. Financing and advising: optimal financial contracts with venture-capitalists. Journal of Finance 58, 2059-2085.

Chandler, A., 1966. Strategy and Structure. Doubleday \& Co., New York.

Chatterjee, S., 1986. Types of synergy and economic value: the impact of acquisitions on merging and rival firms. Strategic Management Journal 7, 119-139.

Christie, A.A., Joye, M.P., Watts, R.L., 2003. Decentralization of the firm: theory and evidence. Journal of Corporate Finance 9, 3-36.

Clarke, J.E., Fee, C.E., Shawn, T., 2004. Corporate diversification and asymmetric information: evidence from stock market trading characteristics. Journal of Corporate Finance 10, 105-129.

Crémer, J., 1980. A partial theory of the optimal organization of bureaucracy. Bell Journal of Economics 11, 683-693.

Crémer, J., unpublished manuscript. Theory of institutions, University of Toulouse.

Denis, D.K., Shome, D.K., 2005. An empirical investigation of corporate asset downsizing. Journal of Corporate Finance 11, 427-448.

Garicano, L., 2000. Hierarchies and the organization of knowledge acquisition. Journal of Political Economy 108, 874-904.

Grinblatt, M., Titman, S., 2001. Financial Markets and Corporate Strategy. McGraw-Hill.

Harris, M., Kriebel, C.H., Raviv, A., 1982. Asymmetric information, incentives, and intrafirm resources allocation. Management Science 28, 604-620.

Holmström, B., Tirole, J., 1997. Financial intermediation, loanable funds, and the real sector. Quarterly Journal of Economics 112, 663-692.

Huson, M.R., MacKinnon, G., 2003. Corporate spinoffs and information asymmetry between investors. Journal of Corporate Finance 9, 481-503.

Inderst, R., Müller, H., 2003. Internal versus external financing: an optimal contracting approach. Journal of Finance 58, $1033-1062$.

Inderst, R., Müller, H., 2004. The effect of capital market characteristics on the value of start-up firms. Journal of Financial Economics 72, $319-356$.

Inderst, R., Laux, C., 2005. Incentives in internal capital markets: capital constraints, competition and investment opportunities. RAND Journal of Economics 36, $215-228$.

Inderst, R., Müller, H., Wärneryd, K., 2007. Distributional conflict in organizations. European Economic Review 51, $385-402$.

Jensen, M., 1986. Agency cost of free cash flow, corporate finance, and takeovers. American Economic Review 76, 323-329.

Krishnaswami, S., Subramanian, V., 1999. Information asymmetry, valuation and the corporate spin-off decision. Journal of Financial Economics 53, 73-112.

Lewellen, W.G., 1971. A pure financial rationale for the conglomerate merger wave. Journal of Finance 26, 521-537.

Martin, J.D., Sayrak, A., 2003. Corporate diversification and shareholder value: a survey of the literature. Journal of Corporate Finance 9, 37-57.

Maskin, E., Qian, Y., Xu, C., 2000. Incentives, information, and the organizational form. Review of Economic Studies 67, 359-378.

Matsusaka, J., Nanda, V., 2002. Internal capital markets and corporate refocusing. Journal of Financial Intermediation 11, 176-211.

McNeil, C.R., Moore, W.T., 2005. Dismantling internal capital markets via spin-off: effects on capital allocation efficiency and firm valuation. Journal of Corporate Finance 11, 253-275.

Meyer, M., Milgrom, P., Roberts, J., 1992. Organizational prospects, influence costs, and ownership changes. Journal of Economics and Management Strategy 1, 9-35. Qian, Y., Roland, G., Xu, C., 2006. Coordination and experimentation in M-form and U-form organizations. Journal of Political Economy 114, 366-402.

Radner, R., 1992. Hierarchy: the economics of management. Journal of Economic Literature 30, 1382-1415.

Radner, R., Van Zandt, T., 1992. Information processing in firms and returns to scale. Annales d'Economie et de Statistiques $25-26,265-298$.

Rajan, R., Servaes, H., Zingales, L., 2000. The cost of diversity: the diversification discount and inefficient investment. Journal of Finance 55, 35-80.

Renucci, A., 2000. Optimal relationships with value-enhancing financiers. Working Paper. University of Toulouse.

Repullo, R., Suarez, J., 2004. Venture capital finance: a security design approach. Review of Finance 8, 75-108.

Scharfstein, D.S., Stein, J.C., 2000. The dark side of internal capital markets: divisional rent seeking and inefficient investments. Journal of Finance 55, $2537-2565$. Schmidt, K.M., 2003. Convertible securities and venture capital finance. Journal of Finance 58, 1139-1166.

Shleifer, A., Vishny, R.W., 1989. Management entrenchment: the case of manager-specific assets. Journal of Financial Economics 25, 123-140.

Simon, H.A., 1973. Applying information technology to organization design. Public Administration Review 33, $268-278$.

Stein, J.C., 1997. Internal capital market and the competition for corporate resources. Journal of Finance 52, 111-133.

Stein, J.C., 2003. Agency, information and corporate investment. In: Constantinides, G.M., Harris, M., Stulz, R.M. (Eds.), Handbook of the Economics of Finance, vol. 1A. Elsevier, North Holland, pp. 111-165.

Tirole, J., 2005. The theory of corporate finance. Princeton University Press, New Jersey.

Van Zandt, T., 1998. Organizations with an endogenous number of information processing agents. In: Majumber, M. (Ed.), Organizations with Incomplete Information: Essays in Economic Analysis. Cambridge University Press, Cambridge.

Villalonga, B., 2004. Diversification discount or premium: new evidence from the business information tracking series. Journal of Finance 59, 479-506.

Walter, G.A., Barney, J.B., 1990. Management objectives in mergers and acquisitions. Strategic Management Journal 11, 79-86.

Weber, Y., Shenkar, O., Ravesh, A., 1996. National and corporate cultural fit in mergers/acquisitions: an exploratory study. Management Science 42, $1215-1227$.

Williamson, O., 1975. Markets and Hierarchies: Analysis and Antitrust Implications. Collier Macmillan Publishers, New York. 